\title{
Preparation, storage and microbiological quality of ready-to-serve low cholesterol masala paneer
}

\author{
Monika Rani ${ }^{1}$, Randheer Singh Dabur ${ }^{1}$, Sudhi Ranjan Garg ${ }^{2}$ and Vijay Jadhav ${ }^{2}$ \\ 1. Department of Livestock Products Technology, Lala Lajpat Rai University of Veterinary and Animal Sciences, \\ Hisar-125004, Haryana, India; 2. Department of Veterinary Public Health \& Epidemiology, Lala Lajpat Rai University of \\ Veterinary and Animal Sciences, Hisar-125004, Haryana, India \\ Corresponding author: Monika Rani, email: vermasanchit45@gmail.com \\ RSD: dabur1958@gmail.com, SRG: srgarg415@yahoo.com, VJ: vetviju@gmail.com
}

Received: 13-04-2014, Revised: 28-05-2014, Accepted: 31-05-2014, Published online: 30-06-2014

doi: $10.14202 /$ vetworld.2014.443-447

How to cite this article: Rani M, Dabur RS, Garg SR and Jadhav V (2014) Preparation, storage and microbiological quality of ready-to-serve low cholesterol masala paneer, Veterinary World 7(6): 443-447.

\begin{abstract}
Aim: To prepare ready-to-serve masala paneer products with very little cholesterol and to assess their nutritional composition and microbiological safety under refrigerated conditions.

Materials and Methods: Brine dipped and dry salted masala paneer products were prepared using fresh skim milk (fat $0.5 \%$ and solid not fat (SNF) 8.7\%), vegetable oil (soybean oil), coriander leaves (1\%), mint leaves (1\%) and green chilies $(0.3 \%)$, roasted and grounded cumin seeds $(0.3 \%)$ and black pepper $(0.3 \%)$. These products were then analyzed for total energy, fat, protein, cholesterol, calcium $(\mathrm{Ca})$ and magnesium $(\mathrm{Mg})$. The samples were examined for standard plate counts (SPC), yeast and mold counts, coliform counts, Staphylococcus aureus counts and E. coli count at 2 days interval up to 8 days and also for the presence of Salmonella spp. and Listeria monocytogenes.
\end{abstract}

Results: These products with very low cholesterol content $(<2 \mathrm{mg} / 100 \mathrm{~g})$ can be labeled as cholesterol free paneer products. Nutritional evaluation revealed that $15 \%$ of the Daily Reference Value of energy, $38 \%$ of protein and $20 \%$ of calcium could be met from single serving of $100 \mathrm{~g}$ of ready-to-serve products. SPC, coliform count and yeast and mold counts in the products were very low while E. coli. Staphylococcus aureus, Salmonella spp. and Listeria monocytogenes were not detected. The products were microbiologically safe and remained so for at least 6 days on refrigeration storage.

Conclusion: It is concluded that the ready-to-serve low cholesterol paneer products were hygienic and microbiologically safe.

Keywords: cholesterol free, microbiological safety, nutrition, paneer.

\section{Introduction}

Paneer is a tempting, nutritious and delicious indigenous dairy product obtained by acid and heat coagulation of milk. In India, where most people are vegetarian in dietary habits, milk products constitute major source of protein and other essential nutrients. Growing tensed environment and diets rich in fat combined with lack of exercise and physical work are leading to cardiovascular and many other serious health problems in the society. The researchers and medical boards have considered milk fat as a possible risk factor in causing coronary heart diseases because of the presence of more saturated fatty acids and cholesterol.

Cholesterol content in dairy products has become a public health issue requiring development of low fat and low cholesterol milk products [1]. Conventional paneer is quite rich in cholesterol and fat. Paneer because of being prolific in moisture and other nutrients is very prone to contagion. The spoilage in paneer occurs mainly due to the growth of microorganisms like yeasts and molds which bring about various physiochemical changes leading to the development of off-flavour in

Copyright: The authors. This article is an open access article licensed under the terms of the Creative Commons Attribution License (http://creativecommons.org/licenses/by/2.0) which permits unrestricted use, distribution and reproduction in any medium, provided the work is properly cited. the product. Unhygienic paneer can also be a potential source of pathogens like Staphylococcus aureus $[2,3]$ Salmonella spp., Escherichia coli and Listeria monocytogenes $[4,5]$. These pathogens find their way into food products through various sources and become potential threat to public health.

Keeping in mind the above facts, the present study was carried to develop ready-to-serve masala paneer products with very little cholesterol and to evaluate their nutritional composition and microbiological stability under refrigerated conditions.

\section{Materials and Methods}

Preparation of low cholesterol paneer products: Fresh skim milk (fat $0.5 \%$ and SNF 8.7\%) was obtained from the institutional dairy production unit and adjusted to $6 \%$ fat with vegetable oil (soybean oil) and mixed with an electric stirrer. Milk was heated to $85^{\circ} \mathrm{C}$ and then cooled to $72^{\circ} \mathrm{C}$. Thoroughly washed coriander leaves $(1 \%)$, mint leaves $(1 \%)$ and green chilies $(0.3 \%)$ were added to the milk. The milk was coagulated with citric acid monohydrate of SRL (Sisco Research Lab. India), Mumbai procured through local supplier and the coagulum was collected on muslin cloth. Roasted and grounded cumin seeds $(0.3 \%)$ and black pepper $(0.3 \%)$ were sprinkled while collecting the coagulum and then pressed@2-3kg/cm² for 20 minutes (Figure-1). 


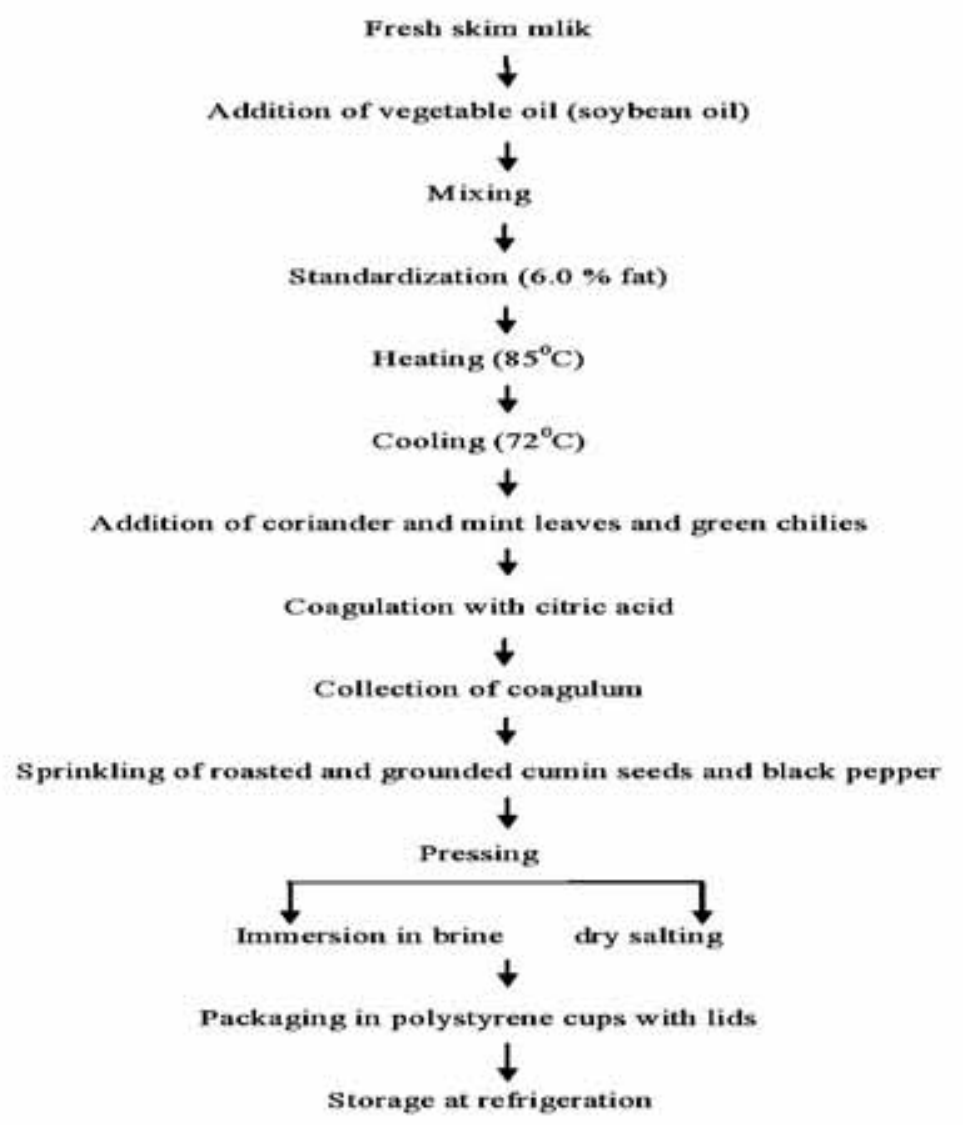

Figure-1: Flow chart for ready-to-serve low cholesterol masala paneer

Preparation of brine dipped (BD) masala paneer: Paneer prepared as described above was cut into cubes $\left(2.5 \mathrm{~cm}^{3}\right)$. The cubes were dipped in brine solution $(5 \%)$ for 15 minutes and then hygienically packed in polystyrene cups with lids. The storage was done at refrigeration temperature.

Preparation of dry salted (DS) masala paneer: Paneer was cut into cubes $\left(2.5 \mathrm{~cm}^{3}\right)$ which were dry salted (3\%) for 15 minutes and then packed hygienically in polystyrene cups with lids. The product was stored under refrigeration $\left(4 \pm 1^{\circ} \mathrm{C}\right)$.

Nutritional evaluation: The brine dipped (BD) and dry salted (DS) masala paneer samples were analyzed for total energy (by calculation), fat, protein, cholesterol, $\mathrm{Ca}$ and $\mathrm{Mg}$. Fat content was measured by Majonnier method [6]. The analysis of protein, cholesterol, Ca and $\mathrm{Mg}$ was done by auto analyzer (Erba Mannheim) using fully auto analyzer kit.

\section{Evaluation of cholesterol}

Extraction of lipids: Total lipids from sample were extracted according to the method of Angelo et al. [7] with slight modification. Paneer sample (25 g) was homogenized with $100 \mathrm{ml}$ solvent (chloroform: methanol, 3:1) for 5 minutes. It was kept for 10 minutes and then this mixture was put on Buchner suction filter. Residue was homogenized two times again as above. Combined organic filtrates were transferred to separating funnel. Two volumes of $0.88 \%$ aqueous potassium chloride were added and the funnel was shaken vigorously. Non lipid material was partitioned to upper aqueous phase by keeping the funnel undisturbed for $12 \mathrm{~h}$. Lower layer was drawn off and dried over sodium sulphate. Lower phase after removing upper phase, if cloudy was made clear by addition of a few drops of methanol. Lipid extract was dried to a constant weight at $60^{\circ} \mathrm{C}$, first in water bath and then in hot air oven.

Cholesterol: Extracted lipids were diluted five times with solvent (chloroform: methanol, 3:1). Total cholesterol was assessed in auto analyzer using standard diagnostic kit and expressed as mg cholesterol/100 gram sample.

Storage study: Masala paneer products were stored at refrigeration temperature $\left(4 \pm 1^{\circ} \mathrm{C}\right)$. Microbiological analysis was done at 2 days interval up to 8 days.

Microbiological analysis: Standardized paneer obtained from the Department of Livestock Products Technology, Lala Lajpat Rai University of Veterinary and Animal Sciences, Hisar was used as control. Microbiological analysis of the paneer product samples was carried out by the methods prescribed by Bureau of Indian Standards [8]. The samples were examined for SPC, yeast and mold counts, coliform counts, $S$. aureus counts and $E$. coli count. The samples were also examined for the presence of Salmonella spp. and L. monocytogenes.

\section{Results}

Nutritional composition of developed products: The nutritional composition of the developed masala paneer products has been presented in Table-1. Total fat 
Table-1: Nutritional composition of ready-to-serve low cholesterol masala paneer products

\begin{tabular}{llll}
\hline Nutritional constituents (Per 100g) & Standardized paneer & \multicolumn{2}{c}{ Masala Paneer } \\
\cline { 3 - 4 } & & BD & DS \\
\hline Total energy (Calories) & $311.47 \pm 0.01$ & $272.01 \pm 0.20$ & $289.40 \pm 0.02$ \\
Total fat (g) & $25.55 \pm 0.04$ & $21.25 \pm 0.26$ & $23.0 \pm 0.00$ \\
Total cholesterol $(\mathrm{mg})$ & $134.30 \pm 0.07$ & $1.69 \pm 0.18$ & $1.90 \pm 0.10$ \\
Total proteins $(\mathrm{g})$ & $18.63 \pm 0.02$ & $18.52 \pm 0.24$ & $18.50 \pm 0.0$ \\
Total carbohydrates $(\mathrm{g})$ & $1.75 \pm 0.06$ & $1.67 \pm 0.22$ & $1.50 \pm 0.10$ \\
Total ash $(\mathrm{g})$ & $2.21 \pm 0.03$ & $2.35 \pm 0.16$ & $2.40 \pm 0.20$ \\
Calcium $(\mathrm{mg})$ & $233.02 \pm 0.01$ & $234.39 \pm 0.23$ & $234.60 \pm 1.20$ \\
Magnesium $(\mathrm{mg})$ & $23.89 \pm 0.02$ & $23.99 \pm 0.21$ & $24.02 \pm 1.30$ \\
\hline
\end{tabular}

Values are mean \pm SEM of five replicates. BD - Brine dipped DS - Dry salted

Table-2: Microbiological quality of masala paneer products during storage under refrigeration condition.

\begin{tabular}{lllllll}
\hline Microbial count (Log10 cfu/g) & Products & \multicolumn{5}{c}{ Storage ( Days) } \\
\cline { 3 - 7 } & & $\mathbf{0}$ & $\mathbf{2}$ & $\mathbf{4}$ & $\mathbf{6}$ & $\mathbf{8}$ \\
\hline Standard plate count & BD & 2.74 & 3.10 & 4.28 & 4.33 & 4.76 \\
& DS & 2.43 & 2.80 & 3.35 & 4.21 & 4.38 \\
Coliform count & BD & 1.00 & 1.60 & 1.77 & 1.95 & 2.11 \\
& DS & ND & 1.47 & 1.69 & 1.84 & 1.95 \\
Yeast and mould counts & BD & ND & 1.60 & 2.04 & 2.25 & 2.54 \\
& DS & ND & 1.47 & 1.95 & 2.17 & 2.38 \\
\hline
\end{tabular}

BD - Brine dipped DS - Dry salted ND - Not Detectable

was lower in the BD (21.25\%) and DS (23\%) masala paneer products as compared to standardized paneer (25.55\%). Cholesterol content of the BD and DS products were $1.69 \mathrm{mg}$ and $1.9 \mathrm{mg}$ per $100 \mathrm{~g}$, respectively in comparison to $311.47 \mathrm{mg}$ per $100 \mathrm{~g}$ in standardized paneer.

Protein, carbohydrates, total ash, calcium and magnesium contents in the developed products are given in Table-1.

Microbiological quality on storage at refrigeration temperature: The microbiological quality of the two products at different storage intervals is shown in Table- 2. On day $0, \mathrm{SPC}$ in the $\mathrm{BD}$ and DS products was $550 / \mathrm{g}$ and $270 / \mathrm{g}$, respectively while coliform count was $10 / \mathrm{g}$ in the BD and undetectable in DS. It was observed from the data that SPC had shown an increasing trend during entire storage period, an increase was observed to the level of $58010^{2} / \mathrm{g}$ and $24010^{2} / \mathrm{g}$ while coiliform count increased up to 130/g and 90/g in the BD and DS products, respectively at the end of storage (8th day).

Yeasts and molds were not detected on day 0 , but these become detectable in both the products after 2 days and subsequently increased in number. The Yeast and Mould count was increased up to 350/g and 245/g in the BD and DS products, It is important to mention this in the results respectively at the end of storage (8th day).

E. coli, S. aureus, Salmonella spp. and L. monocytogens were absent in both the products at all stages of storage.

\section{Discussion}

Nutritional composition of developed products: Vegetable oil used to prepare the paneer of acceptable tenure and flavor might have less retention by the protein matrix of paneer. Fresh coriander leaves added in the product also might contribute towards more retention of moisture in the product and consequently lower fat content. Ankita [9] also observed 21\% fat and $55 \%$ moisture content in masala paneer prepared from skimmed milk with added vegetable oil. Similar observations were also made by Bajwa et al. [10] who worked on vegetable impregnated paneer. They reported that protein content declined with the addition of coriander and mint leaves in vegetable impregnated paneer. This may be attributed because of lower protein content of the coriander and mint leaves and some losses may occur during brine dipping leading to loss of some salt soluble proteins during immersion in brine.

Low cholesterol in paneer was attained because the skimmed milk has only $15 \%$ total cholesterol of the whole milk and the vegetable oil does not contain cholesterol.

The results revealed that $15 \%$ of Daily Reference Value (DRV) of energy, 38\% DRV of protein, $20 \%$ DRV of calcium and $6 \%$ of magnesium could be met from a single serving of $100 \mathrm{~g}$ of the developed product. The product can be categorized as cholesterol free product according to the provision in Nutritional Labeling and Education Act 1990 of United State Food and Drug Administration wherein $<2 \mathrm{mg}$ cholesterol per serving is classified as cholesterol free product.

Microbiological changes of developed products on storage at refrigeration temperature: SPC had shown increasing trend with extended storage. However, on storage at refrigeration temperature, SPC was well within the permissible limits under (FSSAI) Regulations, [11] for paneer i.e. 50,000/g upto 6 days in $\mathrm{BD}$ products and up to 8 days in DS product (Figure-2). This may be attributed to the presence of salt and spices. Bactericidal and bacteriostatic properties of spices are well documented in the literature $[12,13$, 14]. There was gradual rise in the SPC, attaining $\log _{10}$ $\mathrm{cfu} / \mathrm{g}$ values of $4.76\left(5.8 \times 10^{4} / \mathrm{g}\right) 4.38\left(2.4 \times 10^{4} / \mathrm{g}\right)$ in BD 


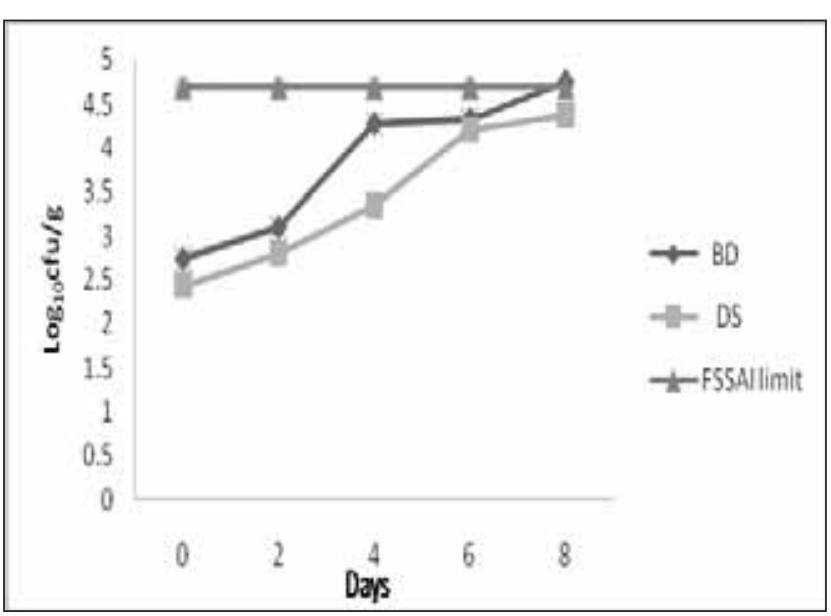

Figure-2: SPC in low cholesterol masala paneer products

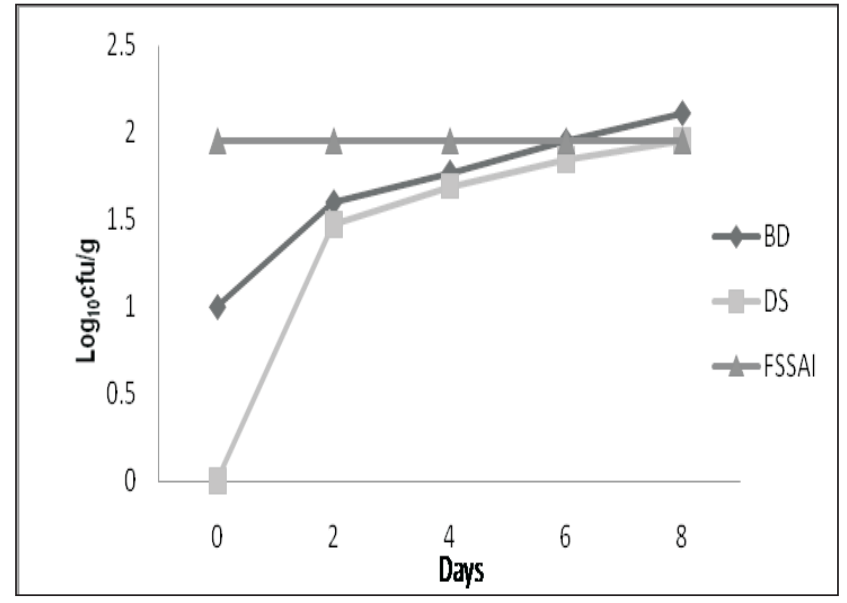

Figure-3: Coliform counts in low cholesterol masala paneer products

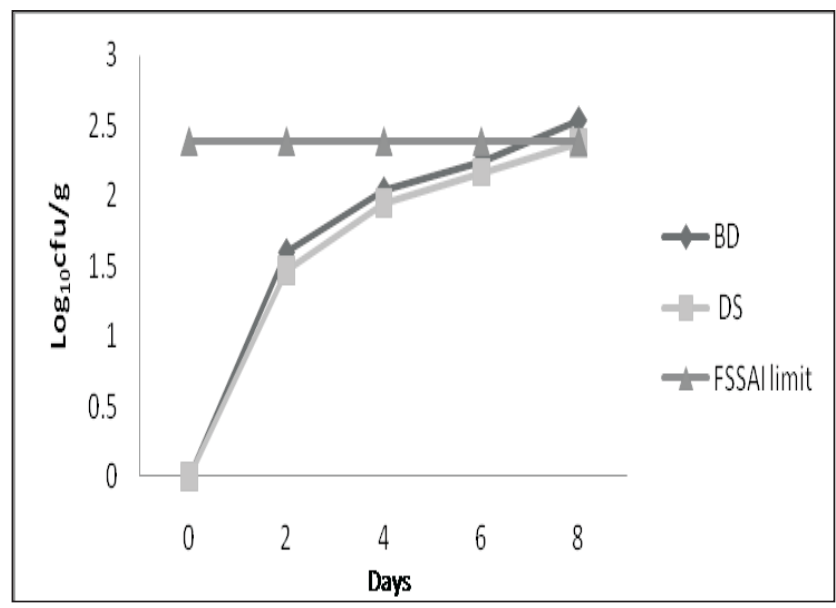

Figure-4: Yeast and mold counts in low cholesterol masala paneer products

and DS products, respectively after 8 days. Results obtained in the present study are in agreement with the results reported by Ankita [9] who observed SPC (log $\mathrm{cfu} / \mathrm{g}$ ) of BD products on day zero was 4.15 , which increased up to the level of 5.78 on day 10 . Whereas, DS products had SPC count of 4.08 when freshly prepared. The number was reached to the levels of 5.29 on day 10 of storage.

Coliform counts also showed gradual rise in numbers in both the products but remained below the FSSAI prescribed levels (Figure-3). Their counts remained below the permissible limits prescribed by FSSAI (Figure-3) for paneer i.e. not more than 250/g at least up to 6 days. Ankita [9] has also reported similar observations on the microbiology of the products developed by her.

As is evident from the Table- 2 and Figure- 4 data with the advancement of storage period, yeast and molds counts crossed the permissible limits of FSSR for paneer i.e. not more than $250 / \mathrm{g}$. Results obtained in the present study are in agreement with the result reported by Ankita [9] who observed log cfu/g values of masala paneer on day zero was 2.32 in BD products, increased up to the level of 3.31 on day 10 of storage. In case of DS products, the number was found to be 2.19 when assessed immediately after preparation. And the counts increased to the levels of 3.07 at day 10 of storage. Bajwa et al. [10] has also reported similar changes in microbiology of the vegetable impregnated and salted paneer products on storage. Whereas both the products were free from pathogens during the entire study period.

\section{Conclusion}

It is concluded that the ready-to-serve low cholesterol products were hygienic and microbiologically safe. The technologies generated may be explored for value addition to paneer for preparing a safe ready to serve product. The acceptance of the cholesterol free paneer product may be explored.

\section{Authors' contributions}

RSD have designed the study. SRG and VJ have planned the research experiments. MR performed the research experiments. MR and SG drafted and revised the manuscript. All authors read and approved the final manuscript.

\section{Acknowledgements}

The authors are highly thankful to Dean, College of Veterinary Science and Animal Husbandry, LLR 
University of Veterinary and Animal Sciences, Hisar, India for providing necessary funds and facilities to carry out the investigation.

\section{Competing interests}

The authors declare that they have no competing interests.

\section{References}

1. Kai, S.H1., Bongard, V., Simon, C., Ruidavets, J. B., Arveiler, D., Dallongeville, J., Wagner, A., Amouyel, P., Ferrières, J. (2013) Low-fat and high-fat dairy products are differently related to blood lipids and cardiovascular risk score. Eur J Prev Cardiol. Sept.3 [Epub ahead of print].

2. Pinto, M. S., de, C.A. F., Pires, A. C. D. S. (2011) the effects of nisin on Staphylococcus aureus count and the physicochemical properties of Traditional Minas Serro cheese. Int Dairy J. 21(2):90-96.

3. Pires, S. M., Vieira, A. R., Perez, E., Lo, F. W. D., Hald,T. (2012) Attributing human foodborne illness to food sources and water in Latin America and the Caribbean using data from outbreak investigations. Int J Food Microbiol. 152(3): 129-38.

4. Chaves, C1.,Arias, M.L. (2009) Characterization of Listeria monocytogenes isolates obtained from raw cheese samples acquired from different Costa Rican producer zones. Arch Latinoam Nutr. 59(1):66-70.

5. Torres, V., Mendoza, B. M., Castro, R. J., Gomez, A. C. A., Garay, M. L.E., Navarro, H. V., Villarruel, L. A. (2012) Incidence of Salmonella, Listeria monocytogenes, Escheri- chia coli $\mathrm{O} 157: \mathrm{H7}$, and Staphylococcal enterotoxin in two types of Mexican fresh cheeses. J Food Protect. 75(1):7984.

6. AOAC (1995) Official Methods of Analysis. 16th edn. Association of Official Analytical Chemists, Washington, D.C. p367-384

7. Angelo, A. J. St., Vercellotti, J.R., Legendre, M.G., Vinnett, C.H., Kuan, J.W., James, C. Jr. and Dupuy, H.P. (1987) Chemical instrumental analysis of warmed over flavor in beef. JFood Sci. 52(5): 1163-1168.

8. BIS (1989) Handbook of Food Analysis, Part XI, Dairy Products, Bureau of Indian Standards, Manak Bhawan, New Delhi.

9. Ankita (2009) Studies on the ready to serve low cholesterol masala paneer. M.Sc. Thesis submitted to Chaudhary Charan Singh Haryana Agricultural University, Hisar.

10. Bajwa, U., Kaur, J. and Sandhu, K.S. (2005) Changes occurring during storage of vegetable impregnated paneer. $J$ Food Sci Tech Mys. 42 (2): 152-157.

11. FSSR (2011) Food Safety and Standard Regulations. Food Safety and Standard Authority of India, Ministry of Health and Family Welfare, Govt. of India, New Delhi.

12. Sethi, V. and Anand, J. C. (1975).Quality characteristics of some Indian mustard. Indian Food Packer.29:21-23

13. Zaika, L. L. and Kissinger, J. C. (1979). Effects Of some spices on acid production by starter culture. J Food Protect 42:572-576.

14. Sethi, V. (1994) Low cost Technology for Preservation of Fruits and Vegetables. IARI, New Delhi: Research Bulletin. Division of Fruits and Horticultural Technology. p110-112. 